\title{
RESPONSES OF THE MORPHOLOGICAL TRAITS OF ELM (ULMUS MINOR' 'UMBRACULIFERA') LEAVES TO AIR POLLUTION IN URBAN AREAS (A CASE STUDY OF TEHRAN METROPOLITAN CITY, IRAN)
}

\author{
ABBASI, S. ${ }^{1}-$ HOSSEINI, S. M. ${ }^{2 *}-$ KHORASANI, N. ${ }^{3}-$ KARBASSI, A. ${ }^{4}$ \\ ${ }^{1}$ Faculty of Environment and Energy, Department of Environmental Science, Science and \\ Research Branch, Islamic Azad University, Tehran, Iran \\ ${ }^{2}$ Faculty of Natural Resources \& Marine Sciences, Tarbiat Modares University (TMU) \\ Noor, Mazandaran, Iran \\ ${ }^{3}$ Faculty of Natural Resources, Department of the Environment, University of Tehran \\ Karaj, Iran
}

${ }^{4}$ Faculty of Environment University of Tehran, University of Tehran, Karaj, Iran

*Corresponding author

e-mail: hosseini.tmu@gmail.com

(Received 25 $5^{\text {th }}$ Jul 2016; accepted $1^{\text {st }}$ May 2018)

\begin{abstract}
In this study, changes in the morphological traits of the leaves of elm tree (Ulmus minor 'Umbraculifera') were investigated against the air pollution in Tehran City, capital of Iran. For this purpose, the healthy and fully developed leaves were sampled from even-aged trees of the same diameter class from 3 districts of Tehran City with different traffic volume and air pollution load. Then, the micromorphological traits of the stoma including length, width, density, size, stomatal shape, trichome density, and theoretical stomatal resistance were measured using Scanning electron microscopy (SEM) images. The macro-morphological traits, including length, width, shape, and area of the leaf, as well as the number of teeth on the blade, length of petiole, and asymmetry of the blade were measured. Determining the wet and dry weights and leaf turgor, the specific leaf area and relative water content were estimated. The results showed that the macro-morphological traits of the leaves were resistant and did not change significantly in the presence of air pollutants. In the contaminated areas, unlike the stomatal density that showed an increase, the stomatal size decreased. With increasing leaf thickness in the polluted areas, the stomatal density also showed an increase. Due to the inherent resistance of the leaves of elm tree to the reduction of leaf water potential, the failure of the photosynthesis rate, caused by the presence of pollutants, is compensated. In the species of elm, the traits of stomatal density and size are better descriptors for reflecting leaf changes in different environmental conditions.
\end{abstract}

Keywords: air pollutants, urban areas, stomatal density, stomatal size, green space development, resistance plant

\section{Introduction}

Air pollution in urban and industrial areas affects the survival of plant species. Although plants in industrial environments can be effective in controlling and reducing air pollution, they are affected by air pollutants and damaged (Dineva, 2004). Different plants show different sensitivity and performance in the face of air pollution (Dineva, 2004; Verma and Singh, 2006; Stevovi et al., 2010). The response of plants to environmental conditions and changes is strongly associated with their structural and functional characteristics (Gostin, 2009; Wang et al., 2011). Environmental changes 
lead to anatomical and morphological changes in the organs of plants (Verma and Singh, 2006; Wuytack et al., 2010; Stevovi et al., 2010).

Several studies have been done on the structure and anatomy of vegetative organs under conditions of environmental pollution (Arriaga et al., 2014; Chaturvedi et al., 2013; Lima et al., 2000; Kardel et al., 2010; Balasooriya et al., 2009). Plant species that are resistant to air pollution can show adaptations and continue to grow. The resistance of different tree species to air pollution is different, and some species are able to withstand pollutants and can remain normal and healthy (Magtoto et al., 2013). Among plant organs, leaves are more sensitive to environmental tension because most of the physiological processes, such as photosynthesis, are carried out through leaves. However, leaves have greater flexibility to adapt to the environmental conditions (Dineva, 2004; Rani et al., 2006). Hence, studying the reactions and adaptations of leaves in the face of air pollutants can be a good indicator of the performance of plant species in polluted environments. In cities and industrial areas, wooden species and trees, with their high leaf area, are effective in controlling and reducing air pollutants (Saebo et al., 2012; Petrova et al., 2013).

Having informed on the capability and performance of species and determining the ability of different species to deal with air pollution can be the first step to maximize the benefits of trees in urban and industrial areas (Escobedo et al., 2011; Saebo et al., 2012). It also provides a suitable basis for the selection of plant species and improving air quality (Wang et al., 2011).

Tehran, as the largest city in Iran, is considered as one of the world's populous cities (Naddafi et al., 2012). The city faces problems such as high population density and heavy traffic jam. It is the most industrialized city of Iran. Many industries such as power plants, refineries, furnaces, and metal processing and smelting plants are located on the outskirts of the city (Kermani et al., 2016). In Tehran, air pollution is a serious problem, and pollutants from vehicle traffic are a major contributor to this pollution (Kermani et al., 2016, 2003; Naddafi et al., 2012; Salmanzadeh et al., 2015; Kord et al., 2010; Leili et al., 2008; Sowlat et al., 2011). The present study was carried out to study the capabilities and resistance of elm (Ulmus minor 'Umbraculifera') tree against air pollution. The study seeks to answer the question that is it advisable to plant elm tree with the purpose of development of green spaces in urban and industrial areas with high rate of air pollution. Accordingly, changes in the morphological traits of the leaf of street-side trees of Tehran City were investigated.

\section{Materials and methods}

\section{Study area}

Tehran is the capital city of Iran, located in $35^{\circ} 36^{\prime}$ northern latitude and $50^{\circ} 53^{\prime}$ eastern longitude. The average altitude of the city is $1191 \mathrm{~m}$ above sea level. The maximum and minimum levels of temperature are, respectively, $22.5{ }^{\circ} \mathrm{C}$ and $11.2{ }^{\circ} \mathrm{C}$. Majority of industries are located on the western part of the city and its suburbs where the prevailing wind blows towards the east-west direction (Alijani and Safavi, 2005). Tehran's topographic conditions are such that the mountains surround the city from the north and east and these elevated barriers prevent the evacuation of pollutants from the city. Moreover, on the west side, due to being openness, suburban pollutants also enter the city with the help of winds (Alijani and Safavi, 2005; Golbaz et al., 2010). 


\section{Research procedure}

Three districts of Tehran City were selected to take samples from the leaves of streetside elm trees. These three districts in terms of the traffic volume and air pollution load were divided in two categories of low emission (Site 1: Chitgar Station) and high emission (Site 2: Azadi Street and Site 3: Gisha Bridge) (Fig. 1).

The first site, Chitgar Station, was located in a forest park on the western outskirt of the city with a dense green space, where the traffic volume was very low. The distance of Site 1 from the nearest highway (Tehran-Karaj Highway, as most crowded highway of Iran) was more than $1000 \mathrm{~m}$. Despite the low traffic of this station, under the influence of the prevailing wind direction, numerous small and large industrial sites in the region, and the discussed topographic conditions, this site deals with the consequences of air pollution.

Since majority of the particles released from the vehicles are sedimentated at the shortest distance from the emission source, attempts were made to collect the samples from the leaves of road-side trees.

Samples in Site 2 were collected from street-side trees in Azadi Square, the west and southwest of Tehran. Traffic volume in Azadi Square is very heavy. However, due to wide streets and pedestrian walkways, as well as lower density of residential and commercial buildings, air conditioning is better in this site, compared to the Site 3 .

Site 3 is located in the central part of Tehran. A vehicle overpass, the intersection of two highways, proximity to residential and commercial structures, such as higher education institutions and offices have caused massive traffic jams and reduced air conditioning in this part of the city.

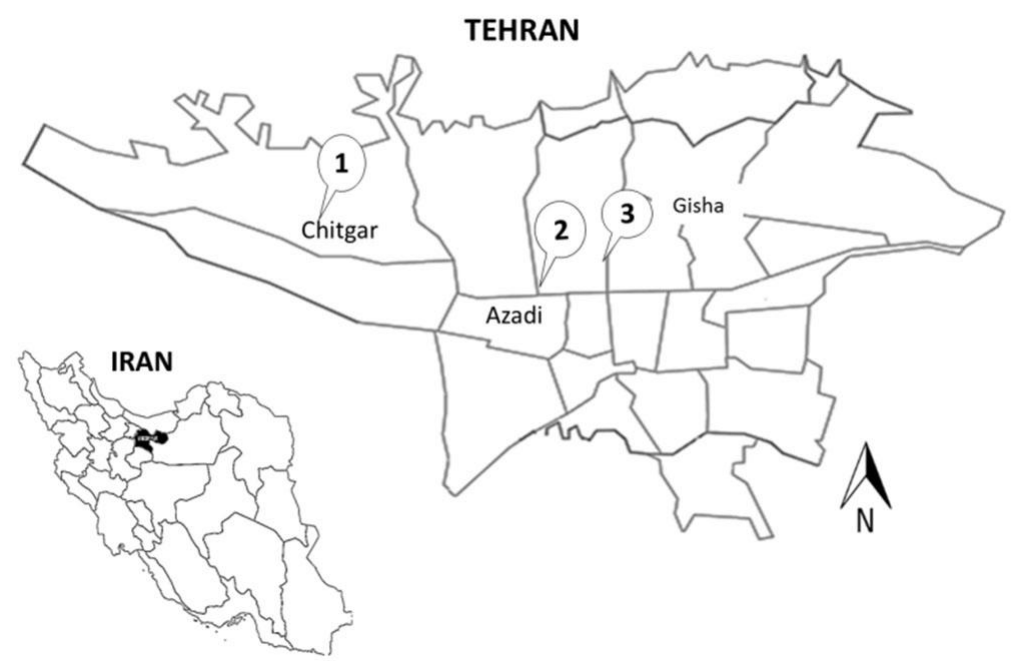

Figure 1. Situation of the sampling sites in Tehran City and in Iran

Figure 2 shows air quality indicators of Tehran in 2014. The data were obtained from the annual report on air quality of Tehran in 2014 published by Tehran Air Quality Control Company. The Site 1 was located in a forest park in the outskirt of the city, where there was no active air monitoring station nearby. The nearest air monitoring stations to the Sites 2 and 3 were placed at a distance of about $500 \mathrm{~m}$ away from the sampling area (Fig. 2). 

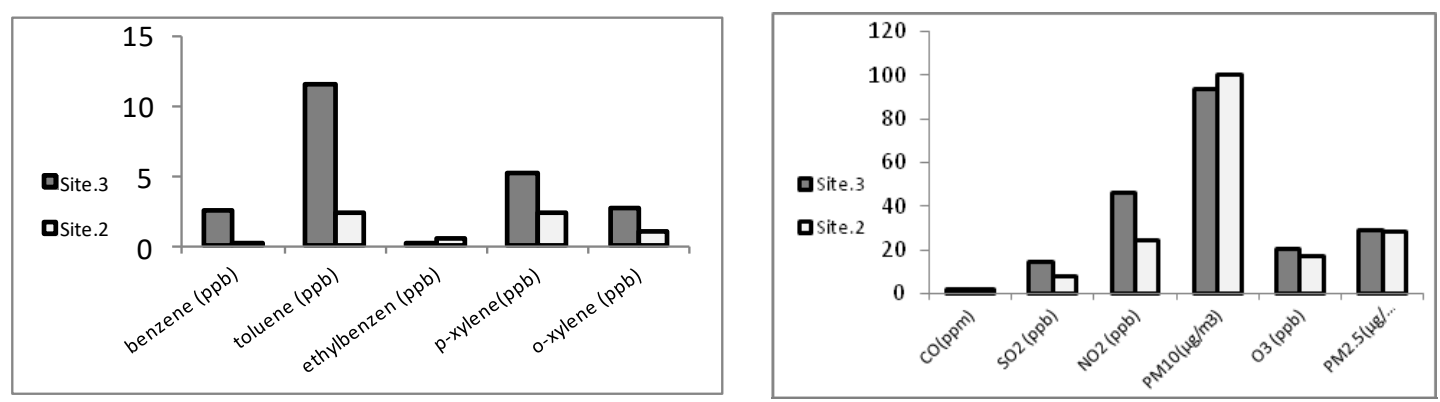

Figure 2. Air quality indicators of Tehran City in 2014 obtained from Tehran Air Quality Control Company

\section{Sampling and analysis}

\section{Traits of elm tree}

Elm (Ulmus SPP.) includes 20 to 45 species, scattered in the northern hemisphere and mountainous parts of tropical regions (Wheeler and Manchester, 2007). Iran is one of the countries wherein some elm species have been expanded (Oladi et al., 2013). Because some species of elm, due to their vault-like crown, are widely used in development of green spaces in urban areas.

\section{Leaf sampling}

In each sampling site, 5 healthy and disease-free trees with the least distance from the street were selected randomly. The orientation of the trees towards the street and the direction of sunlight and wind were considered to be the same. The trees were even aged and selected from similar diameter classes. The sampling was done at the end of the growing season in the second half of September, 2014.

The perfectly healthy leaves were collected from the street side outermost part of the canopy. To ensure the opening of stomata, the leaves were collected at 10 to $11 \mathrm{am}$. They were placed in a wrapped nylon in an ice tank with minimal hand contact and transferred to the laboratory in the shortest time. To take images with Scanning Electron Microscopy (SEM), the leaves were dried in a dry place away from sunlight at normal room temperature.

Using the images taken from the lower leaf surface, micro-morphology traits of the leaves, including Stomatal pore length $(\mu \mathrm{m})(\mathrm{SL})$, Stomatal pore width $(\mu \mathrm{m})(\mathrm{SW})$, Stomatal density (SD), Stomatal pore shape (SPS) (length to width ratio of stomatal), Stomatal Pore Surface (SPS), and Theoretical minimal stomatal resistance (Rs) were measured. Assuming the oval shape of the pores, the SPS was measured for other pores using Equation 1 (Balasooriya et al., 2009). The Rs was also calculated using Equation 2 (Balasooriya et al., 2009).

$$
\begin{gathered}
S P S=\frac{(S L \times S W \times \pi)}{4} \\
R s=\left(4 \frac{\pi}{n} \times \pi \times S l \times S w \times D\right)+\left(S l+\frac{S W}{4 n \times S I \times S I W \times D}\right)
\end{gathered}
$$


where Rs is the stomatal resistance $\left(\mathrm{sm}^{-1}\right), 1$ is the stomatal pore depth $(\mathrm{m}), \mathrm{D}$ is the water vapor diffusion coefficient in air $\left(24.2 \times 10^{-6} \mathrm{~m}^{2} \mathrm{~s}^{-1}\right.$ at $\left.20^{\circ} \mathrm{C}\right)$, and $\mathrm{n}$ is the stomatal density (number of stomata $\mathrm{m}^{-2}$ ). Stomatal depth was considered to be $10 \mu \mathrm{m}$ (Samson et al., 2000; Olyslaegers et al., 2002). To study the macro-morphological parameters of the leaves, from each tree base, the images of 50 leaves were prepared in a JPEG format with the help of a scanner. According to which, the parameters of Leaf length (LL), Leaf Width (LW), LS (length to width ration), Leaf area, teeth density, petiole length, and fluctuating asymmetry blade (FA) (Eq. 3) were calculated using Image J software (Kovacic and Nikolic, 2005).

$$
F a=\frac{\|W 1-W r\|}{(W 1+W r)}
$$

in which $\mathrm{Wl}$ is the left half area of leaf blade and $\mathrm{Wr}$ refers to the right half area.

To measure SLA, 30 leaves were collected from each tree. From each leaf, $4 \mathrm{~cm}^{2}$ pieces were punched and dried for $24 \mathrm{~h}$ at $60{ }^{\circ} \mathrm{C}$. The weight of the dried parts was measured by a digital scale with a precision of $0.001 \mathrm{~g}$. Then, the SLA was calculated using Equation 4. SLA = area of the punched parts/weight of the punched parts $\left(\mathrm{cm}^{2} \mathrm{~g}^{-1}\right)$.

To measure Relative Water Content (RWC), 20 leaves were sampled from each tree and punched into the $4 \mathrm{~cm}^{2}$ pieces. The wet weight of the punched pieces was measured. These pieces were placed in distilled water in low light intensity for $4 \mathrm{~h}$. After measuring their turgor weight, they were dried at $60{ }^{\circ} \mathrm{C}$ for $24 \mathrm{~h}$ and weighed (Ritchie and Nguyen, 1990) (Eq. 4).

$$
R W C=\lfloor(\text { wet weight }- \text { wet weight }) \mid(\text { turgor weight }- \text { dry weight })\rfloor \times 100
$$

\section{Statistical analysis}

The normality of the data was tested by Kolmogorov-Smirnov test in SPSS 16.0 software. Homogeneity of variance was tested using Levene's test. To compare the data, ANOVA was used. For multiple comparisons of the average values, Duncan, KruskalWallis, and Mann-Whitney U tests were used.

\section{Results and discussion}

As Figure 2 suggests, the level of most of the pollutants in Gisha Bridge is higher than Azadi Square. This is mainly due to the lower wind speed, high density of buildings, heavy traffic, and transport of worn out vehicles at the central parts of Tehran City (Shamsipour et al., 2013; Naddafi et al., 2012; Leili et al., 2008). Figure 3 shows a SEM image taken from LSS of elm leaf.

\section{Micro-morphological traits of elm leaves}

The results of statistical testes showed a significant difference between the average values of the leaf micro-morphological traits in tree sampling stations, including SL $(\mathrm{Sig}=0 / 000), \mathrm{SSH}(\mathrm{Sig}=0 / 000)$, stomatal density $(\mathrm{Sig}=0 / 000)$, stomatal pore surface $(\mathrm{Sig}=0 / 001)$, and RS (Sig =0/000) (Fig. 4). No significant difference was found between the measured values of $\mathrm{SW}$ in the three sampling sites $(\mathrm{Sig}=0 / 289)($ Table 1$)$. 


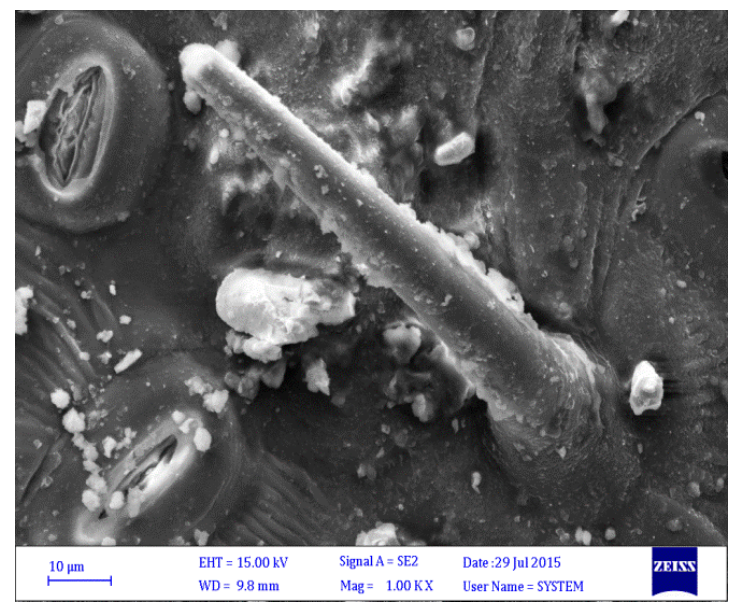

$\mathbf{a}$

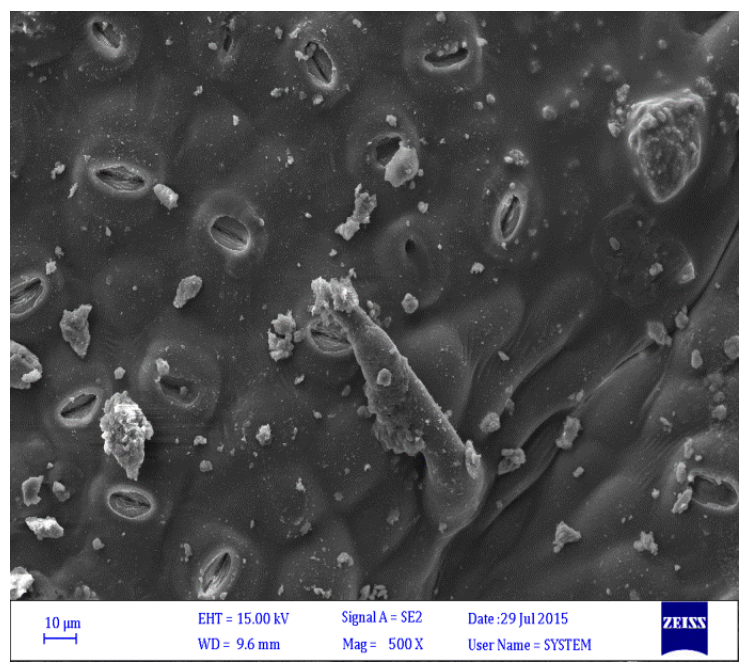

c

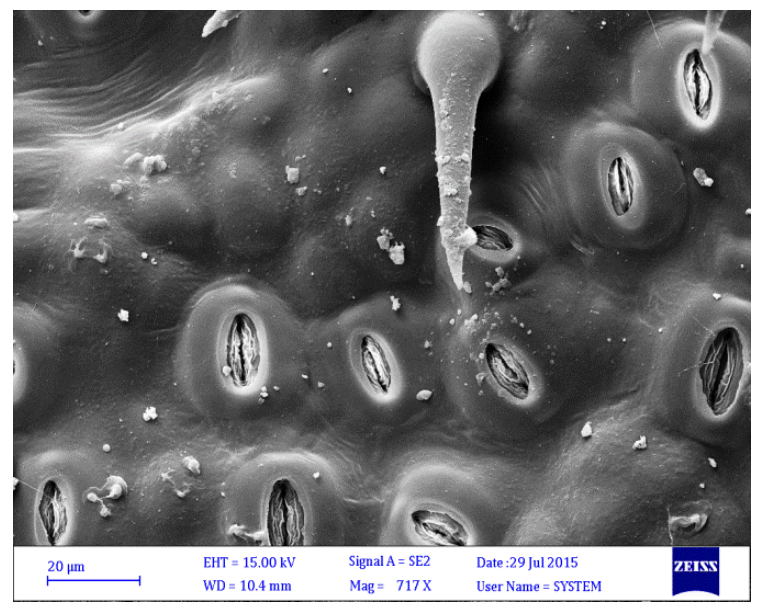

b

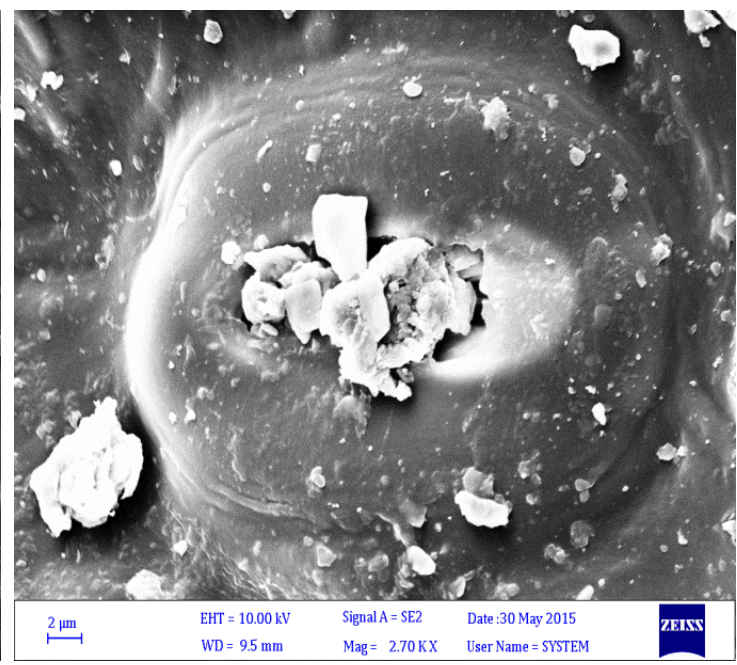

d

Figure 3. SEM images taken the lower surface pores of elm leaf. a Chitgar Station, $\boldsymbol{b}$ Gisha Bridge, $\boldsymbol{c}$ Azadi Square, $\boldsymbol{d}$ complete blockage of stomata by airborne particulates

According to the table, the SL value, compared to Chitgar Station, showed a decline of $27 \%$ in Azadi Square and $19 \%$ in Gisha Bridge (Fig. 4a). In addition, the values of stomatal length-to-width ratio in Azadi Square and Gisha Bridge were respectively 27\% and $17 \%$ lower than that in Chitgar Station. (Fig. 4b). Comparison of the average stomatal density in the studied areas showed that in Azadi and Gisha, 31\% and 144\% increase in density was observed in comparison with Chitger (Fig. 4c). Stomatal pore surface was reduced in the polluted sites so that its value at Azadi and Gisha was $31 \%$ and 26\% lower than Chitgar, respectively (Fig. 4d). The Rs increased in Gisha Bridge compared to Chitgar and was $30 \%$ less than Azadi (Fig. 4e).

The response of stomata to tension and mechanisms for reducing and controlling the input of pollutants into leaves are one of the most important traits of plants under stress conditions (Andersen, 2003). Balasooriya et al., 2009). Stomatal density is an important eco-physiologic parameter, which affects gas exchange between the atmosphere and plant (Lake et al., 2001; Uprety et al., 2002; Pompelli et al., 2010). 
Table 1. A comparison on the average values of the micro-morphological traits of Elm leaves in the three sampling sites

\begin{tabular}{|c|c|c|c|c|}
\hline Parameter & Location & mean $\pm \mathrm{SE}$ & Sig. & $\begin{array}{r}\text { Significant } \\
\text { difference }\end{array}$ \\
\hline \multirow{3}{*}{ Stomatal pore length $(\mu \mathrm{m})$} & Chitgar & $16.84 \pm 0.37$ & \multirow{3}{*}{0.000} & \multirow{3}{*}{$* *$} \\
\hline & Azadi Square & $12.29 \pm 0.25$ & & \\
\hline & Gisha Bridge & $13.56 \pm 0.42$ & & \\
\hline \multirow{3}{*}{ Stomatal pore width $(\mu \mathrm{m})$} & Chitgar & $6.92 \pm 0.33$ & \multirow{3}{*}{0.289} & \multirow{3}{*}{$\mathrm{ns}$} \\
\hline & Azadi Square & $6.53 \pm 0.18$ & & \\
\hline & Gisha Bridge & $6.31 \pm 0.24$ & & \\
\hline \multirow{3}{*}{ Stomatal pore shape } & Chitgar & $2.62 \pm 0.15$ & \multirow{3}{*}{0.000} & \multirow{3}{*}{$* *$} \\
\hline & Azadi Square & $1.91 \pm 0.05$ & & \\
\hline & Gisha Bridge & $2.17 \pm 0.05$ & & \\
\hline \multirow{3}{*}{ Stomatal density (mm2) } & Chitgar & $322.43 \pm 29.01$ & \multirow{3}{*}{0.000} & \multirow{3}{*}{$* *$} \\
\hline & Azadi Square & $420.87 \pm 17.30$ & & \\
\hline & Gisha Br. & $780.03 \pm 82.01$ & & \\
\hline \multirow{3}{*}{ Stomatal pore surface $(\mu \mathrm{m} 2)$} & Chitgar & $92.47 \pm 0.55$ & \multirow{3}{*}{0.001} & \multirow{3}{*}{$* *$} \\
\hline & Azadi Square & $63.54 \pm 0.26$ & & \\
\hline & Gisha Bridge & $68.33 \pm 0.45$ & & \\
\hline \multirow{3}{*}{$\begin{array}{l}\text { Theoretical minimal stomatal } \\
\text { resistance (sm-1) }\end{array}$} & Chitgar & $90.2 \pm 10.3$ & \multirow{3}{*}{0.000} & \multirow{3}{*}{$* *$} \\
\hline & Azadi Square & $63.4 \pm 4.33$ & & \\
\hline & Gisha Bridge & $100.13 \pm 18.2$ & & \\
\hline
\end{tabular}

Ns $=$ no statistically significant difference, $*=$ a statistically significant difference at the probability of $95 \%, * *=$ a statistically significant difference at the probability of $99 \%$

Researchers have found that traits such as stomatal density, epidermal cell density, and stomatal pore length are not hereditary and influenced by environmental conditions. Stomatal pore shape, increased stomatal density, and reduced stomatal pore surface in polluted areas are mechanisms for adapting species to contaminated environments (Wagoner, 1975; Kardel et al., 2010; Wuytack et al., 2010; Rani et al., 2006).

Increasing the stomatal density and reducing the size of the stomach can control and reduce gas exchanges and the entry of pollutants through the stomata (Wuytack et al., 2010; Alves et al., 2008). The entry of pollutants into plants through stomata has an inhibitory effect on plant physiological activities, such as photosynthesis (Younis et al., 2013). Therefore, plants reduce the size of stomata to minimize the entry of pollutants (Verma and Singh, 2006). Plants, which have good resistance to air pollution, can offset photosynthetic deficiency, caused by reduced gas exchange, by increasing pore density.

In the present study, decreasing changes in stomatal pore length, stomatal pore surface, and stomatal pore shape as well as increasing stomatal density from clean areas towards contaminated areas indicates the strong and effective correlation of these parameters with each other in order to adapt the species to air pollution. Many studies highlighted the importance of measurement of stomatal resistance under air pollution conditions (Alessio et al., 2002; Wuytack et al., 2010). Alessio et al. (2002) believed that stomatal resistance increases in areas with heavy traffic to reduce gas exchanges with the surrounding environment under tension conditions (Verma and Singh, 2006; Wuytack et al., 2010). 

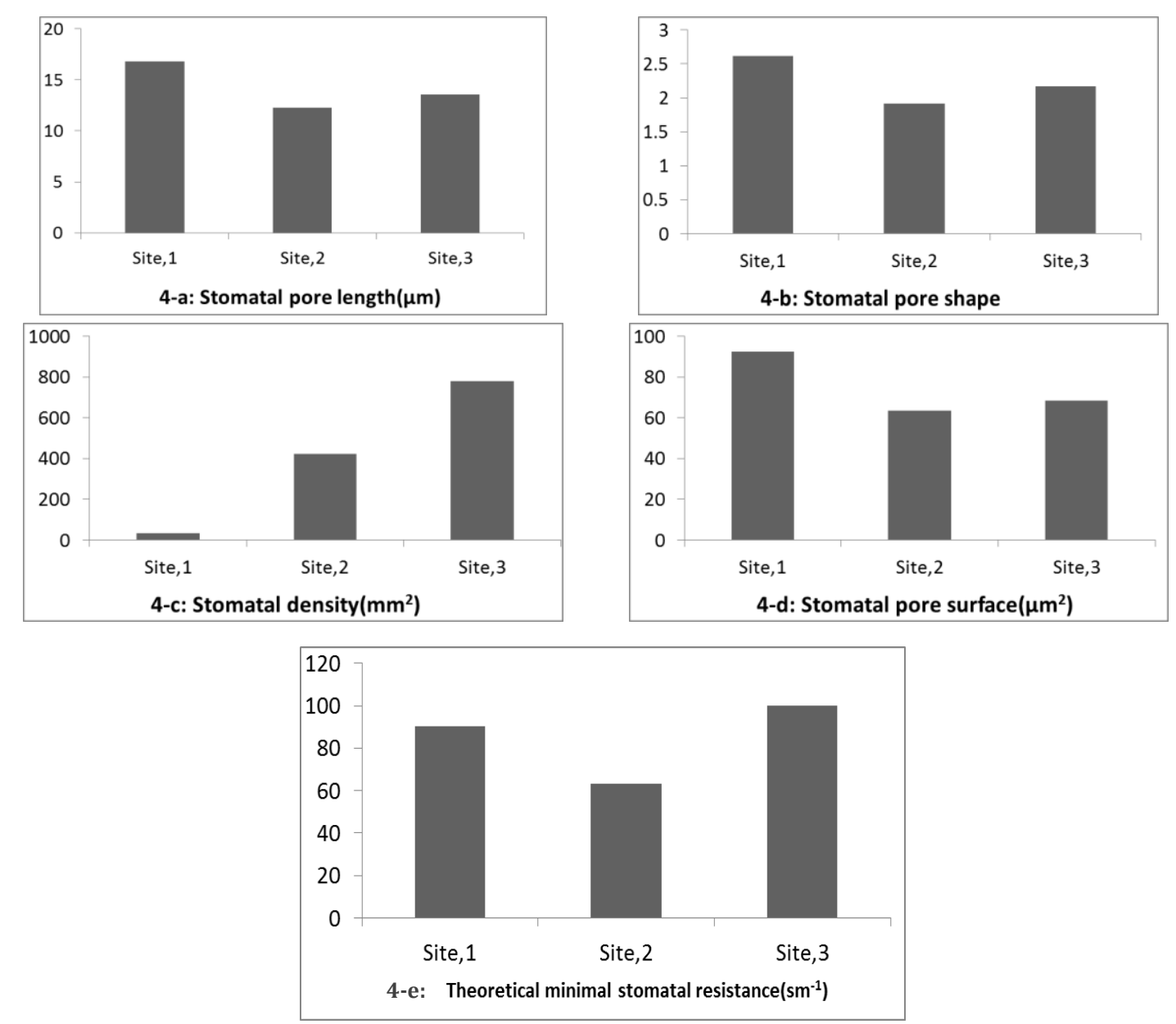

Figure 4. Micro-morphological traits of the lower surface stomata of elm leaf in the sampling sites

In the present study, in the site of Gisha Bridge, in addition to increasing the stomatal density and decreasing the SPS, the Rs showed an increase. This finding is in line with that reported by Wuytack et al. (2010). Mahecha et al. (2013) found that stomatal resistance increases with increasing age. As time passes, stomatal resistance decreases with the activation of tension adaptation mechanisms such as changes in stomatal and enzyme activities. In the present study, Rs reduced as a response to air pollution. The reduction of stomatal resistance in leaves may be due to premature aging caused by environmental tension. In Azadi Site, as the tension increased in leaves, the mechanisms of adaptation were quickly applied; these adaptations caused premature aging, replacement of new leaves, changes in stomatal density and stomatal pore surface, reduced Rs, and increased mesophyll conductance of the leaves. It is also necessary to note that in the present study, stomatal resistance was not measured in the environment; hence the trend of observed stomatal resistance could be due to the effect of local climates and local temperature changes in the sampling areas.

\section{Macro-morphological traits of the leaves of elm tree}

As Table 1 shows, there was found no significant difference between the average values of leaf length $($ Sig. $=0.73)$, leaf width $($ Sig. $=0.64)$, leaf area $($ Sig. $=0.64)$, leaf 
shape (length-to-width ratio of leaf blade) $($ Sig. $=0.40)$, and teeth density $($ Sig. $=0.11)$ in the sampling stations. No significant difference was observed between the average values of fluctuating asymmetry blade $(\mathrm{Sig} .=0.00)$ and petiole length $(\mathrm{Sig} .=0.02)$ in the three sampling sites (Table 2).

Table 2. Statistical analysis of the leaf macro-morphological traits of elm leaf in the sampling sites

\begin{tabular}{|c|c|c|c|c|}
\hline Parameter & Sampling site & mean $\pm \mathrm{SE}$ & Sig. & \\
\hline \multirow{3}{*}{ Leaf length } & Chitgar & $76.79 \pm 4.67$ & \multirow{3}{*}{0.732} & \multirow{3}{*}{$\mathrm{ns}$} \\
\hline & Azadi Square & $76.26 \pm 6.66$ & & \\
\hline & Gisha Bridge & $82.33 \pm 6.62$ & & \\
\hline \multirow{3}{*}{ Leaf width } & Chitgar & $45.97 \pm 3.57$ & \multirow{3}{*}{0.645} & \multirow{3}{*}{$\mathrm{ns}$} \\
\hline & Azadi Square & $50.171 \pm 5.87$ & & \\
\hline & Gisha Bridge & $52.21 \pm 4.89$ & & \\
\hline \multirow{3}{*}{ Leaf area } & Chitgar & $23.46 \pm 2.05$ & \multirow{3}{*}{0.645} & \multirow{3}{*}{$\mathrm{ns}$} \\
\hline & Azadi Square & $26.94 \pm 5.64$ & & \\
\hline & Gisha Bridge & $29.43 \pm 4.61$ & & \\
\hline \multirow{3}{*}{ Length to width ratio of leaf blade } & Chitgar & $1.687 \pm 0.05$ & \multirow{3}{*}{0.404} & \multirow{3}{*}{$\mathrm{ns}$} \\
\hline & Azadi Square & $1.55 \pm 0.07$ & & \\
\hline & Gisha Bridge & $1.60 \pm 0.06$ & & \\
\hline \multirow{3}{*}{ Fluctuating asymmetry blade } & Chitgar & $0.07 \pm 0.01$ & \multirow{3}{*}{0.000} & \multirow{3}{*}{ ** } \\
\hline & Azadi Square & $0.08 \pm 0.010$ & & \\
\hline & Gisha Bridge & $0.17 \pm 0.016$ & & \\
\hline \multirow{3}{*}{ Petiole length } & Chitgar & $6.66 \pm 1.38$ & \multirow{3}{*}{0.026} & \multirow{3}{*}{ * } \\
\hline & Azadi Square & $10.72 \pm 1.51$ & & \\
\hline & Gisha Bridge & $11.76 \pm 0.99$ & & \\
\hline \multirow{3}{*}{ Teeth density } & Chitgar & $2.39 \pm 0.246$ & \multirow{3}{*}{0.115} & \multirow{3}{*}{$\mathrm{ns}$} \\
\hline & Azadi Square & $1.37 \pm 0.35$ & & \\
\hline & Gisha Bridge & $1.60 \pm 0.378$ & & \\
\hline \multirow{3}{*}{ Specific leaf area } & Chitgar & $123.89 \pm 24.4$ & \multirow{3}{*}{0.470} & \multirow{3}{*}{$\mathrm{ns}$} \\
\hline & Azadi Square & $101.92 \pm 11.4$ & & \\
\hline & Gisha Bridge & $91.83 \pm 17.9$ & & \\
\hline \multirow{3}{*}{ Relative water content } & Chitgar & $81.4 \pm 2.55$ & \multirow{3}{*}{$0 / 000$} & \multirow{3}{*}{$* *$} \\
\hline & Azadi Square & $45.4 \pm 4.22$ & & \\
\hline & Gisha Bridge & $83.1 \pm 1.00$ & & \\
\hline
\end{tabular}

Ns $=$ no statistically significant difference, $*=$ statistically significant difference at the probability of $95 \%, * *=$ statistically significant difference at the probability of $99 \%$

Despite the insignificant difference found in the average values of leaf area in three sites, this parameter in the sites of Azadi Square and Gisha Bridge increased respectively by $15 \%$ and $25 \%$ compared to the clean environment in Chitgar Site.

Although the difference between the average values of fluctuating asymmetry blade of the three sites was not confirmed statistically, however the parameter in the sites of Azadi and Gisha Bridge increased respectively by $21 \%$ and $136 \%$ compared to Chitgar. Petiole length in Azadi and Gisha Bridge increased respectively by $61 \%$ and $77 \%$ compared to Chitgar. Although there was found no significant difference in the average 
values of number of teeth per unit area, it reduced respectively by $43 \%$ and $31 \%$ in Azadi and Gisha Bridge, compared to Chitgar. The comparison of the average values of specific leaf area in the sampling sites showed no significant difference among them (Sig. $=0.47)$ comparing the average values of relative water content in the sampling sites showed a significant difference $(\mathrm{Sig}=0 / 00)$ and demonstrated a reduction of $44 \%$ in Azadi Site compared to Chitgar, and it was relatively equal in Gisha Bridge and Chitgar.

Under tension conditions, plants make adaptations that decline gas exchange to the environment in order to reduce contact surface with the polluted environment (Kardel et al., 2010; Arriaga et al., 2014; Verma and Singh, 2006; Balasooriya et al., 2009). The alteration of plant traits in air pollution conditions has been emphasized by many researchers, such as Vujic' et al. (2015) and Glukhov et al. (2015).

Various studies have referred to the reduction of leaf length, leaf width, and leaf area in different plant species under polluted conditions (Kardel et al., 2010; Arriaga et al., 2014; Verma and Singh, 2006; Lima et al., 2000; Balasooriya et al., 2009). Balasooriya et al. (2009) and Verma and Singh (2006) reported that the leaf area in contaminated sites is one of the most important biological markers for contamination monitoring In the present study, the lack of significant difference in mean leaf length, leaf width, leaf area, teeth density, and leaf shape indicated that the macro-morphological variations of elm leaf in polluted sites are not noticeable. The elongation of the leaf and the petiole represents its tolerance to stress (Xu et al., 2009). The findings of the present study confirm those reported by Xu et al. (2009). Incremental changes in petiole length, leaf area, and dry weight from the clean site to the polluted areas showed a positive relationship between these parameters and adaptation of the species to environmental pollutants (Meziane and Shipley, 2001; Chaturvedi et al., 2013).

By reducing the specific leaf area, the amount of chloroplast per unit area of plants increases. Thick leaf has a higher photosynthetic potential. In better words, the concentration of chlorophyll of chloroplast increases in thick leaves and the loss of light or the light passing through the leaves decreases. Consequently, leaf photosynthetic capacity increases.

Those species maintain their photosynthesis rate under tension conditions will be more responsive to stress Insignificant statistical differences in the present study indicated that elm, with the preservation of the photosynthesis potential in the leaves, can resist contamination and continue its growth.

In the polluted sites of Azadi and Gisha Bridge, a reduction in specific leaf area was observed. This is a strategy to improve stress tolerance (Xu et al., 2009). The leaf area variation reflects the growth rate of plants (Meziane and Shipley, 1999). Its reduction reduces water loss and transpiration. It also slows leaf growth and increases resistance of species to tension. Plants that are resistant to tension have higher relative water content (Mahecha et al., 2013). By increasing the thickness of leaves, the water loss is reduced and the relative water content is maintained at an optimum level.

In the present study, there was found no statistical difference between the relative humidity content of clean and contaminated sites, indicating the resistance of the species against the reduction of water content and the increase of transpiration in the presence of air pollutants. Changes in relative water content and specific leaf area revealed a negative relationship between these variables in order to adapt to environmental tension conditions. 
Based on the macro-morphological traits of the elm leaf in this study, it can be argued that the elm leaf is resistant to air pollutants. The elm, in conditions of increased stress, can increase its resistance to airborne contaminants, with adaptations.

\section{Conclusion}

The results of the study suggested that the macro-morphological traits of elm leaf, such as its shape, area, width, and length in the presence of air pollutants do not change significantly and are relatively resistant. The stomatal traits at the lower leaf surface of elm showed that the tree controls the entry of air pollutants by reducing the size of stomata, and stomatal density increases to compensate for the shortage of gas exchanges.

The elm tree can maintain the water contents of leaf tissue to the optimum level, and by increasing the leaf thickness, preserve the photosynthetic potential of its leaves.

In the polluted sites, with increasing leaf thickness, stomatal density also increased. Regarding the inherent resistance of this species to the reduction of leaf water potential, the loss of photosynthetic rate caused by the presence of pollutants was compensated. Reducing the relative water content at Azadi Site can lead to the closure of stomata and eventually reduced photosynthesis. In this site, the species also reduced the size of stomatal pore to cope with this tension. According to the findings of this study, elm can resist against air pollution by applying cost-saving mechanisms. The findings showed that the traits of the elm leaf on polluted sites vary hardly. Hence, based on morphological studies of elm leaf, it can be admitted that the elm species is resistant to air pollution stress in industrialized cities and industrial areas, as well as the sites with high traffic volume. Anatomical studies of leaf can supplement this idea.

In many studies, stomatal density and stomatal pore surface are introduced as a good indicator for well differentiation of the sites with different air quality. Similarly, in elm species these two parameters were obviously better descriptors of leaf changes in different environmental conditions. The findings of the present study indicated that in urban and industrial areas that need green spaces resistant to air pollution, the planting of elm tree can play an effective role in achieving this goal.

\section{REFERENCES}

[1] Alessio, M., Anselmi, S., Conforto, L., Improta, S., Manes, F., Manfra, L. (2002): Radiocarbon as a biomarker of urban pollution in leaves of evergreen species sampled in Rome and in rural areas (Lazio-Central Italy). - Atmospheric Environment 36(34): 54055416.

[2] Alijani, B., Safavi, Y. (2005): The relation between pressure distribution and air pollution concentration in Tehran. - Geographical Research Quarterly 37(51): 39-50 (in Persian).

[3] Andersen, CP. (2003): Source-sink balance and carbon allocation below ground in plants exposed to ozone. - New Phytologist 157: 213-228.

[4] Alves, E. S., Tresmondi, F., Longui, E. L. (2008): Leaf anatomy of Eugenia uniflora L. (Myrtaceae) in urban and rural environments, Sao Paulo State, Brazil. - Acta Botanica Brasilica 22: 241-248.

[5] Ambo-Rappe, R., Lajus, D., Schreider, J. (2011): Heavy metal impact on growth and leaf asymmetry of seagrass, Halophila ovalis. - Journal of Environmental Chemistry and Ecotoxicology 3(6): 149-159. 
[6] Arriaga, M. O., Stampacchio, M. L., Fernández Pepi, M. G., Eleonora, P., Perelman, P. E., Faggi, M. (2014): Use of epidermal characters as bioindicators of environmental pollution. - Multequina 23: 41-53.

[7] Balasooriya, B. L. W. K., Samson, R., Mbikwa, F., Vitharana, U. W. A. (2009): Biomonitoring of urban habitat quality by anatomical and chemical leaf characteristics. Environmental and Experimental Botany 65: 386-394.

[8] Chaturvedi, R. K., Prasad, S., Rana, S., Obaidullah, S. M., Pandey, V., Singh, H. (2013): Effect of dust load on the leaf attributes of the tree species growing along the roadside. Environmental Monitoring and Assessment 85: 383-391.

[9] Dineva, S. B. (2004): Comparative studies of the leaf morphology and structure of white ash Fraxinus americana L. and London plane tree Platanus acerifolia Willd growing in polluted area. - Dendrobiology 52: 3-8.

[10] Escobedo, F. J., Kroeger, T., Wagner, J. E. (2011): Urban forests and pollution mitigation: Analyzing ecosystem services and disservices. - Environmental Pollution 159: 2078-2087.

[11] Glukhov, A. Z., Shtirts, Y. A. (2015): Characteristics of the shape asymmetry of leaf tip and base in Populus nigra L. under industrial dump conditions. - Applied Ecology and Environmental Research 13(3): 819-831.

[12] Golbaz, S., Farzadkia, M., Kermani, M. (2010): Determination of Tehran air quality with emphasis on air quality index (AQI) 2008-2009. - Iran Occupational Health Journal 6(4): 59-65 (in Persian).

[13] Gostin, I. N. (2009): Structural modification induced by air pollutions in Plantago Lanceolata Leaves. - Analele Universitatii din Oradea, Fascicula Biologie. Tom. 16(1): 61-65.

[14] Kardel, F., Wuyts, K., Babanezhad, M., Vitharana, U. W., Wuytack, T., Potters, G., Samson, R. (2010): Assessing urban habitat quality based on specific leaf area and stomatal characteristics of Plantago lanceolata L. - Environmental Pollution 158: 788794.

[15] Kermani, M., Naddaf, K., Shariat, M., Mesbah, A. (2003): Chemical composition of TSP and PM10 and their relations with meteorological parameters in the ambient air of Shariati Hospital District. - Iranian Journal of Public Health 32(4): 68-72 (in Persian).

[16] Kermani, M., Arfaeinia, H., Nabizadeh, R., Alimohammadi, M., Aalamolhoda, A. A. (2016): Levels of PM2.5 associated heavy metals in the ambient air of Sina hospital district, Tehran, Iran. - Journal of Air Pollution and Health 1: 1-6.

[17] Kord, B., Mataji, A., Babaie, S. (2010): Pine (Pinus Eldarica Medw.) needles as indicator for heavy metals pollution. - International Journal of Environmental Science and Technology 7(1): 79-84.

[18] Kovacic, S., Nokolic, T. (2005): Relations between Betula Pendula (Betulaceae) leaf morphology and environmental factors in five region of Croatia. - Acta Biologica Cracoviensia s. Botanica 47(2): 7-13

[19] Lake, J. A., Quick, W. P., Beerling, D. J., Woodward, F. I. (2001): Plant development: signals from mature to newleaves. - Nature 411: 154-155.

[20] Leili, M., Naddafi, K., Nabizadeh, R., Yunesian, M., Mesdaghinia, A. (2008): The study of TSP and PM10 concentration and their heavy metal content in central area of Tehran, Iran. - Air Quality, Atmosphere, and Health 1: 159-166.

[21] Lima, J. S., Fernandes, E. B., Fawcett, W. N. (2000): Mangifera indica and Phaseolus vulgaris in the bioindication of air pollution in Bahia, Brazil. - Ecotoxicology and Environmental Safety 46: 275-278.

[22] Mahecha, G. S., Bamniya, B. R., Nair, N., Saini, D. (2013): Air Pollution Tolerance Index of Certain Plant Species - A Study of Madri Industrial Area Udaipur (Raj.), India. International Journal for Innovative Research in Science and Technology 2(12): 79277929. 
[23] Magtoto, L. M., Mones, D. G., Lomahan, F. P. (2013): Morphoanatomical characterization of Tithonia Diversifolia (Hemsl Gray) growing on sites exposed to vehicular emission. - International Journal of Plant, Animal and Environmental Sciences 3(3): 168-172.

[24] Meziane, D., Shipley, B. (1999): Interacting components of interspecific relative growth rate: constancy and change under differing conditions of light and nutrient supply. Functional Ecology 13: 611-622.

[25] Meziane, D., Shipley, B. (2001): Direct and indirect relationships between specific leaf area, leaf nitrogen and leaf gas exchange effects of irradiance and nutrient supply. Annals of Botany 88(5): 915-927.

[26] Naddafi, K., Sowlat, M. H., Safari, M. H. (2012): Integrated assessment of air pollution in Tehran, over the period from September 2008 to September 2009. - Iranian Journal of Public Health 41(2): 77-86.

[27] Neverova, O. A., Legoshchina, O. M., Bykov, A. A. (2013): Anatomy of leaves of Betula pendula (Roth.) Affected by air emissions in industrial area of Kemerovo City. - Middle East Journal of Scientific Research 17(3): 354-358.

[28] Oladi, R., Matini, H., Sharifi, Z., Masoumi, A. (2013): Comparing the wood anatomy of the field elms (Ulmus carpinifolia Borkh.) native to Gorgan and Komijan. - Iranian Journal of Natural Resources Research 66(1): 69-81 (in Persian).

[29] Olyslaegers, G., Nijs, I., Roebben, J., Kockelbergh, F., Vanassche, F., Laker, M., Verbelen, J. P., Samson, R., Lemeur, R., Impens, I. (2002): Morphological and physiological indicators of tolerance to atmospheric stress in two sensitive and two tolerant tea clones in South Africa. - Experimental Agriculture 38(4): 397-410.

[30] Petrova, S., Yurukova, L., VeLchev, I. (2013): Taraxacum officinale as a biomonitor of metalsand toxic elements (Plovdiv, Bulgaria). - Bulgarian Journal of Agricultural Science 19(2): 241-247.

[31] Pompelli, M. F., Martins, S. C. V., Celin, E. F., Ventrella, M. C., DaMatta, F. M. (2010): What is the influence of ordinary epidermal cells and stomata on the leaf plasticity of coffee plants grown under full-sun and shady conditions? - Brazilian Journal of Biology 70(4): 1083-1088.

[32] Rani, M., Pal, N., Sharma, R. K. (2006): Effect of railway engines emission on the micromorphology of some field plants. - Journal of Environmental Biology 27(2): 373376.

[33] Ritchie, S. W., Nguyen, H. T. (1990): Leaf water content and gas exchange parameters of two wheat genotypes differing in drought resistance. - Crop Science 30(1): 105-111.

[34] Sæbø, A., Popek, R., Nawrot, B., Hanslin, H. M., Gawronska, H., Gawronski, S. W. (2012): Plant species differences in particulate matter accumulation on leaf surfaces. Science of the Total Environment 427-428: 347-354.

[35] Salmanzadeh, M., Saeedi, M., Li, L. Y., Nabi-Bidhendi, G. (2015): Characterization and metals fractionation of street dust samples from Tehran, Iran. - International Journal of Environmental Research 9(1): 213-224.

[36] Samson, R., Vandenberghe, J., Vanassche, F., Nijs, I., Olysalaegers, G., Kockelbergh, F., Lemeur, R., Laker, M. (2000): Detecting Sensitivity to Extreme Climatic Conditions in Tea: Sap flow as a Potential Indicator of Drought Sensitivity Between Clones. - In: Ceulemans, R., Bogaert, J., Deckmyn, G., Nijs, I. (eds.) Topics in Ecology: Structure and Function in Plants and Ecosystems. University of Antwerp, Wilrijk, pp. 267-268.

[37] Shamsipour, A., Najibzadehe, F., Hosseinpoor, Z. (2013): Simulation of Tehran air pollution dispersion model in windy air conditions. - Geography and Environmental Hazards 1(4): 3-4.

[38] Sowlat, M. H., Gharibi, H., Yunesian, M., Tayefeh Mahmoudi, M., Lotfi, S. (2011): A novel, fuzzy-based air quality index (FAQI) for air quality assessment. - Atmospheric Environment 45(12): 2050-2059. 
[39] Stevovic, S., Mikovilovic, V. S., Dragosavac, DC. (2010): Environmental impact on morphological and anatomical structure of Tansy. - African Journal of Biotechnology 9(16): 2413-2421.

[40] Uprety, D. C., Dwivedi, N. J., Mohan, V. R. (2002): Effect of elevated carbon dioxide concentration on the stomatal parameters of rice cultivars. - Photosynthetica 40(2): 315319.

[41] Verma, A., Singh, S. (2006): Biochemical and ultrastructural changes in plant foliage exposed to auto-pollution. - Environmental Monitoring and Assessment 120(1-3): 585602.

[42] Vujic, V., Avramov, S., Tarasjev, A., Barisic Klisaric, N., Zivkovic, U., Miljkovic, D. (2015): The effects of traffic-related air pollution on the flower morphology of Iris pumila - comparison of a polluted city area and the unpolluted deliblato sands (nature reserve). Applied Ecology and Environmental Research 13(2): 405-415.

[43] Wagoner, S. (1975): Leaf cuticular andmorphological variations in Plantago lanceolata as indicators of environmental pollution. - Tennessee Academy of Science 50: 79-83.

[44] Wang, H., Shi, H., Li, Y. (2011): Leaf Dust Capturing Capacity of Urban Greening Plant Species in Relation to Leaf Micromorphology. - International Symposium on Water Resource and Environmental Protection 3: 2198-2201.

[45] Wheeler, E. A., Manchester, S. R. (2007): Review of the wood anatomy of extant Ulmaceae as context for new reports of late Eocene Ulmus woods. - Bulletin of Geosciences 82(4): 329-342.

[46] Wuytack, T., Verheyen, K., Wuyts, K., Kardel, F., Adriaenssens, S., Samson, R. (2010): The potential of biomonitoring of air quality using leaf characteristics of white willow (Salix alba L.). - Environmental Monitoring and Assessment 171(1-4): 197-204.

[47] Xu, F., Guo, W., Xu, W., Wei, Y., Wang, R. (2009): Leaf morphology correlates with water and light availability: What consequences for simple and compound leaves? Progress in Natural Science: Materials International 19(12): 1789-1798.

[48] Younis, U., Bokhari, T. Z., Raza Shah, M. H. (2013): Dust interception capacity and alteration of various biometric and biochemical attributes in cultivated population of Ficus carica L. - IOSR Journal of Pharmacy and Biological Sciences 6(4): 35-42. 